\title{
Analisis Teknologi Informasi dan Komunikasi Dalam Interpersonal Relationship Kehumasan Persekolahan
}

\author{
${ }^{1}$ Yuliawan Kasmahidayat, ${ }^{2}$ Vina Marcia \\ ${ }^{1}$ Universitas Pendidikan Indonesia \\ Email: kasmahidayat@ upi.edu \\ ${ }^{2}$ Magister Teknologi Pendidikan Institut Pendidikan Indonesia \\ Email : marciavina04@gmail.com
}

\begin{abstract}
Pada era Teknologi Informasi dan Komunikasi, proses pembelajaran memiliki perbedaan signifikan dibanding pengajaran sebelumnya. Pengajaran zaman sekarang memanfaatkan teknologi informasi, menuntut guru untuk kreatif sebagai bentuk praktek kehumasan tentang citra materi pembelajaran di sekolah. Guru harus disiapkan untuk mengajarkan bagaimana anak menjadi kreatif dan kritis dalam praktek pencitraan materipelajaran sehingga dapat disukai siswa. Dengan demikian, siswa akan menjadi pribadi yang siap untuk menghadapi perubahan zaman melalui perannya sebagai aktor individual relation (IR). Selama melaksanakan perannya sebagai actor individual relation maka program kehumasan di persekolahan dapat diwakilinya. Adapun bidang kerja yang menjadi target sasaran Individualrelation praktek kehumasan dipersekolahan mencakup model, metode,kurikulum. Praktek individual relations ini sangat diperlukan untuk mewujudkan peningkatan kapasitas, profesionalisme guru, kurikulum yang dinamis, sarana dan prasarana yang handal, dan teknologi pembelajaran yang mutakhirdalam rangka menghadapi era revolusi 4.0. Dalam prakteknya (IR) ditentukan oleh keberadaan dari teknologi informasi untuk mengolah, mengemas dan menampilkan serta menyebarkan informasi pembelajaran yang dalam studi ini mampu menghasilkan kajian virtual learning dan dan E-learning.Pada akhirnya produk dari IR iniakan membuktikan bahwa prkatek kehumasandi persekolahan sangat dibutuhkan.

Kata kunci : teknologi informasi, komunikasi, inovasi, humas pembelajaran.
\end{abstract}

\begin{abstract}
In the era of Information and Communication Technology, the learning process has significant differences compared to previous teaching. Teaching today utilizes information technology, requiring teachers to be creative as a form of public relations practice about the image of learning materials in schools. Teachers must be prepared to teach how children become creative and critical in the practice of imaging learning materials so that they can be liked by students. Thus, students will become individuals who are ready to face the changing times through their roles as individual relations (IR) actors. During carrying out his role as an actor individual relations, the public relations program in schools can be represented. The areas of work that are targeted by individual relations in school public relations practices include models, methods, curriculum. This individual relations practice is indispensable for realizing capacity building, teacher professionalism, a dynamic curriculum, reliable facilities and infrastructure, and the latest learning technology in order to face the revolutionary era 4.0. In practice (IR) is determined by the existence of information technology to process, package and display and disseminate learning information which in this study is able to produce virtual learning and and E-learning studies. In the end, the products of this IR will prove that the public relations practice in schooling is needed. Keywords: information technology, communication, innovation, learning.
\end{abstract}




\section{A. LATAR BELAKANG}

Teknologi informasi dapat dikatakan sebagai ilmu yang diperlukan untuk mengelola informasi agar informasi tersebut dapat dicari dengan mudah dan akurat. Perkembangan teknologi informasi dan komunikasi pada saat ini berkembang semakin pesat, memudahkan dalam berbagai permasalahan, penciptaan informasi, pemeliharaan saluran, transmisi selektif, penerimaan selektif, penyimpanan dan penelusuran, serta penggunaan yang akhirnya adanya evaluasi kritis dan umpan balik. Teknologi informasi dan komunikasi mencakup dua aspek, yaitu teknologi informasi dan teknologi komunikasi (Darmawan, 2013). Teknologi informasi meliputi segala hal yang berkaitan dengan proses, penggunaan alat bantu, manipulasi, dan pengelolaan informasi. Sedangkan teknologi komunikasi adalah segala sesuatu yang berkaitan dengan penggunaan alat bantu untuk memproses dan mentransfer data dari perangkat yang satu dengan yang lainnya. Oleh karena itu, teknologi informasi dan komunikasi adalah dua buah konsep yang tidak terpisahkan. Jadi teknologi informasi dan komunikasi adalah segala kegiatan yang berkaitan dengan pemrosesan, manipulasi, pengelolaan, pemindahan informasi antar media. Dari definisi ini maka seorang actor kehumasan di persekolahan atau IR sangat membutuhkan kemampuan mempratekan teknlogi informasi yang adaptif dengan kehumasan di persekolahan.

Pemanfaatan teknologi informasi dalam bidang pendidikan terbagi dalam 3 kelompok, yaitu memanfaatkan komputer untuk menyampaikan materi pengajaran itu sendiri, yang biasa dikenal dengan istilah Computer Assisted Intructional (CAI) atau Computer Based Training (CBT) dikemas dalam suatu perangkat lunak, Untuk pendistribusian materi ajar melalui jaringan internet, materi ajar dapat dikemas dalam bentuk webpage, ataupun program belajar interaktif (CAI atau CBT) materi ajar ini kemudian ditempatkan di sebuah server yang tersambung ke internet sehingga dapat diambil oleh peserta didik baik dengan menggunakan web browser ataupun File Transper Protocol dan sebagai media komunikasi dengan pakar atau narasumber atau peserta didik yang lain.

\section{B. KAJIAN LITERATUR}

\section{Hakikat Teknologi Informasi}

Secara sederhana, teknologi informasi dapat dikatakan sebagai ilmu yang diperlukan untuk mengelola informasi agar informasi tersebut dapat dicari dengan mudah dan akurat. Teknologi informasi yang mulai popular di akhir tahun 70-an, dihantarkan untuk menjawab tantangan pada masa sebelumnya, istilah teknologi komputer 
Analisis Teknologi Informasi dan Komunikasi Dalam Interpersonal Relationship

atau pengolahan data elektronis atau EDP (Electronic Data Processing) Menurut kamus Oxford (1995) teknologi informasi adalah studi atau penggunaan peralatan elektronika, terutama komputer untuk menyimpan, menganalisis, dan mendistribusikan informasi apa saja, termasuk kata, bilangan dan gambar. Menurut Lucas (2000) menyatakan bahwa teknologi informasi adalah segala bentuk teknologi yang diterapkan untuk memproses dan mengirimkan informasi dalam bentuk elektronis, seperti mikrokomputer, komputer mainframe, pembaca barcode, software pemroses transaksi perangkat lunak untuk lembar kerja, peralatan komunikasi dan jaringan. Everett $\mathrm{M}$ Rogers dalam bukunya Communication Technology (1986) mengemukakan bahwa teknologi informasi merupakan perangkat keras bersifat organisatoris dan meneruskan nilai-nilai sosial dengan siapa individu atau khalayak mengumpulkan, memproses dan saling mempertukarkan informasi dengan individu atau khalayak lain.

Dari definisi diatas tergambar bahwa teknologi informasi baik secara implisit maupun eksplisit tidak sekedar berupa teknologi komputer tetapi teknologi telekomunikasi. Dengan kata lain teknologi informasi adalah gabungan antara teknologi komputer dan telekomunikasi. Teknologi telekomunikasi adalah teknologi yang berhubungan dengan komunikasi jarak jauh. Saluran multimedia tersebut dapat berupa : saluran melalui komunikasi lisan, saluran dengan menggunakan tulisan, komputer pada satuan-satuan kerja dalam organisasi yang online dengan komputer utama, saluran telepon, teleks, facsimile, dan email. Semua media tersebut akan berguna dalam praktek Indvidual Relations (IR) yang diperankan oleh paragurudan siswa, sehingga upaya pencitraan sekolah nya akan lebih positif dan meluas.

\section{Klasifikasi dan cara kerja Sistem Teknologi Informasi dalam mendukung IR}

Berikut adalah klasifikasi sistem teknologi informasi menurut fungsinya dalam upaya memenuhi kebutuhan praktek kehumasan pembelajan di sekolah.

Tabel. 1 Tabel Sistem Teknologi Informasi Menurut Fungsi Sistem

\begin{tabular}{cclcc}
\hline No & Sistem teknologi informasi & \multicolumn{1}{c}{ Definisi } & Contoh \\
\hline 1 & Embedded IT System & $\begin{array}{l}\text { Sistem teknologi informasi yang } \\
\text { melekat pada produk lain }\end{array}$ & Sistem VCR \\
& & Sistem teknologi informasi yang \\
dirancang untuk melakukan tugas- & ATM \\
& tugas khusus & & \\
& & Sistem teknologi informasi yang \\
& digunakan untuk melakukan aktivitas & PC \\
& General Purpose IT System bersifat umum & \\
\hline
\end{tabular}

(Sumber: Teknologi Informai dan Komunikasi : Darmawan, 2007) 
Sedangkan menurut ukurannya dari fungsi sistem teknologi informasi dalam praktek kehumasan pebelajaran di kelas dapat dilihat pada tabel berikut.

Tabel 2 . Tabel Sistem Teknologi Informasi Menurut Ukuran

\begin{tabular}{cc}
\hline No & Sistem teknologi informasi \\
\hline 1 & Superkomputer \\
2 & Mikrokomputer \\
3 & Mainframe \\
5 & Minikomputer \\
6 & Mikrokontroler \\
\hline
\end{tabular}

(Sumber: Teknologi Informai dan Komunikasi : Darmawan, 2007)

Di bawah ini adalah salah satubagan hasil analisis peta fungsi Teknologi informasi dalam prakteknya pada kehumasan pembelajaran di sekolah.

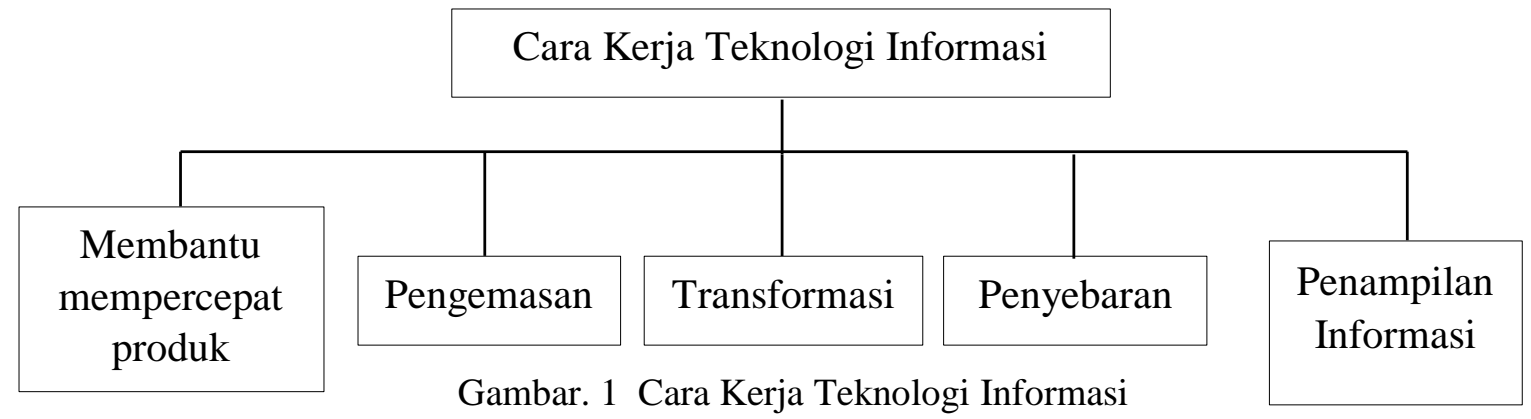

Bagan diatas menggambarkan cara kerja teknologi informasi yang memiliki 2 aspek, yaitu aspek keluasan (broad) dan aspek kedalaman (base).

\section{Manfaat TIK dalam Kehumasan Bidang Pendidikan}

Ditinjau dari praktek IR di persekolahan maka keberadaan dari TIK ini dapat dilihat dari upaya untuk meningkatkan efektivitas dan efisiensi pelaksanaan proses pendidikan, yang mencakup (a) adanya alat teknologi pendidikan, yaitu hardware; (b) adanya program pendidikan, yaitu software; (c) menganalisis dan mendesain urutan atau langkah-langkah belajar berdasarkan tujuan yang ingin dicapai dengan metode penyajian yang serasi serta penilaian keberhasilannya. 
Analisis Teknologi Informasi dan Komunikasi Dalam Interpersonal Relationship Kehumasan Persekolahan

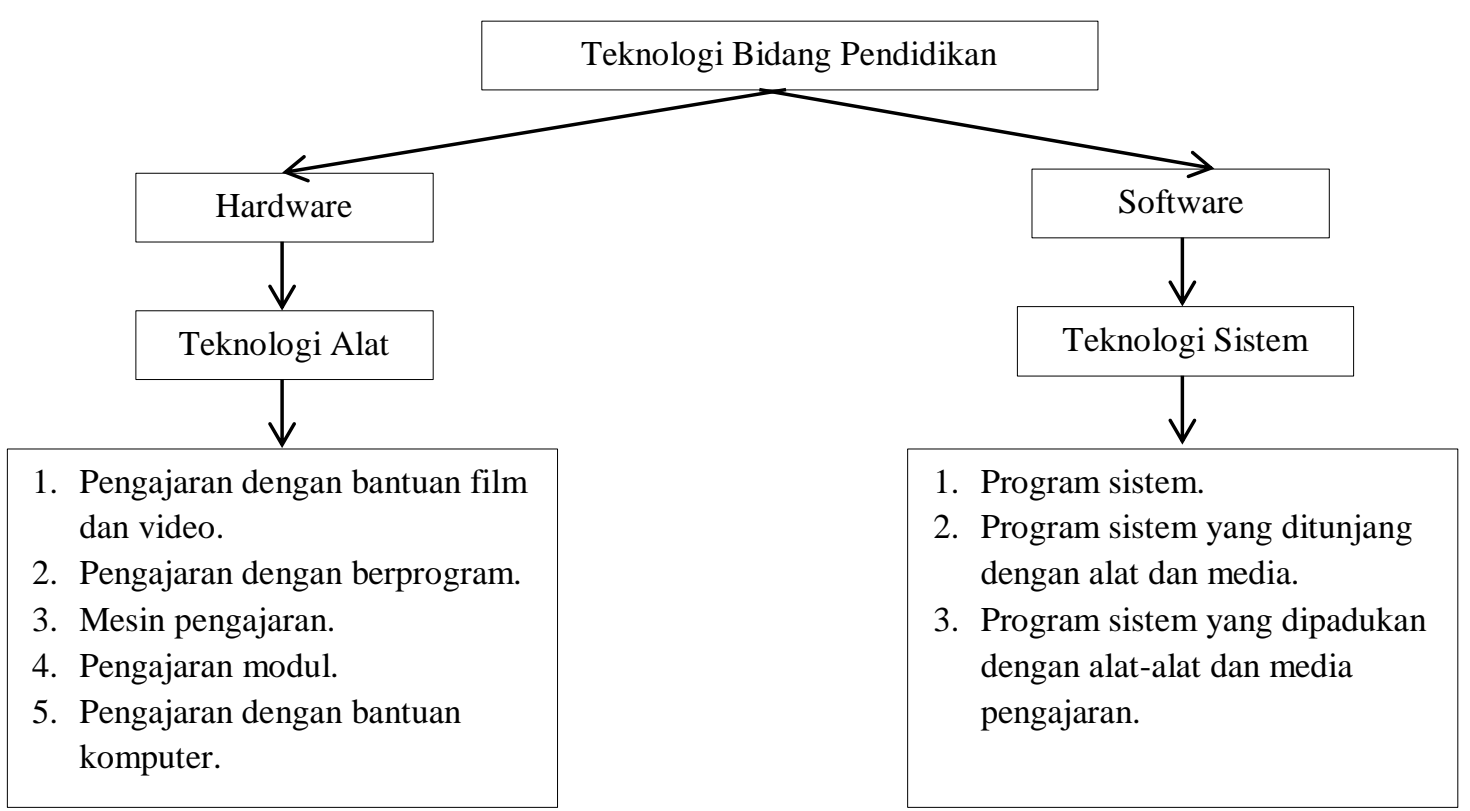

Gambar. 2 Bagan Teknologi dalam bidang pendidikan (Sumber: Teknologi Informai dan Komunikasi : Darmawan, 2007)

Bagan diatas merupakan bagan teknologi dalam bidang pendidikan yang meliputi 2 bentuk, yaitu perangkat keras (hardware) dan perangkat lunak (software). Adapun dalam penerapannya, penerapan teknologi perangkat keras dalam pendidikan dikenal sebagai teknologi alat sedangkan penerapan teknologi perangkat lunak disebut juga teknologi sistem. Contoh model pengajaran yang menggunakan teknologi alat, diantaranya pengajaran dengan bantuan film dan video, pengajaran dengan berprogram, mesin pengajaran, pengajaran modul, dan pengajaran dengan bantuan komputer. Sedangkan program pembelajaran atau perencanaan pembelajaran dengan menggunakan pendekatan sistem, program pengajaran ini dapat dilakukan melalui program sistem, yaitu pengajaran tidak membutuhkan alat dan media canggih tetapi bahan ajar dan proses pembelajaran disusun secara sistem, program sistem yang ditunjang dengan alat dan media, serta program sistem yang dipadukan dengan alat-alat dan media pengajaran.

\section{Inovasi Pendidikan dalam praktek Kehumasan di Sekolah}

Inovasi pendidikan adalah inovasi untuk memecahkan masalah dalam pendidikan. Inovasi pendidikan mencakup hal-hal yang berhubungan dengan komponen sistem pendidikan, baik dalam arti sempit, yaitu tingkat lembaga pendidikan, maupun arti luas, yaitu sistem pendidikan nasional. Dalam konteks kehumasan makainovasi ini dapat diperankan oleh para aktor akademik di tingkat sekolah baik siswa maupun guru, sehingga peran dari aktor 
sebagai Individual Relation dapat pendidikan, serta mengarah pada terlihat kontribusinya.

Inovasi dapat dikreasikan sesuai pemanfaatannya, yang menciptakan hal baru, memudahkan dalam dunia antaranya adalah sistem pendidikan sekolah yang terdiri atas kurikulum, tata tertib, dan manajemen organisasi pusat sumber belajar. Selain itu, yang lebih penting adalah inovasi dilakukan pada sistem pembelajaran (yang berperan di dalamnya adalah guru) karena secara langsung yang melakukan pembelajaran di kelas ialah guru. Keberhasilan pembelajaran sebagian besar tanggung jawab guru. Dengan demikian guru ini menjadi jangkar dalam kemajuan. Inovasi di sekolah, terjadi pada sistem sekolah yang meliputi komponen-komponen yang ada. Di

upaya pencitraan sekolah melalui perannya sebagai actor IR.

Inovasi pendidikan adalah suatu ide, barang, metode yang dirasakan atau diamati sebagai hal yang baru bagi seseorang atau sekelompok orang (masyarakat), baik berupa hasil inversi (penemuan baru) atau discovery (baru ditemukan orang), yang digunakan untuk mencapai tujuan pendidikan atau untuk memecahkan masalah yang dihadapi.

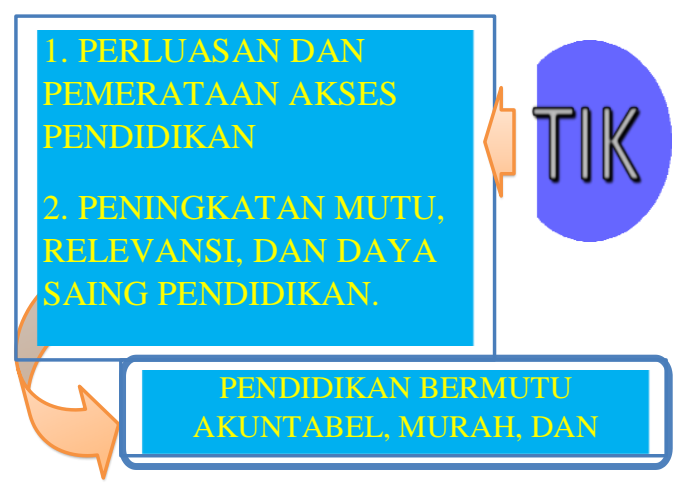

Gambar.3 Peta Inventori TIK dalam praktek Kehumasan

Tabel. 3 Perubahan Paradigma Pembelajaran dalam Praktek Kehumasan di Persekolahan

\begin{tabular}{ll}
\hline \multicolumn{1}{c}{ DARI } & \multicolumn{1}{c}{ KE } \\
\hline Teacher Centered Intruction & Student Centered Intruction \\
Studying once a life & Life -long learning \\
Isolated Institutions & Cooperative Institutions \\
Information Delivery & Informations exchange \\
Passive Learning & Activ/inquiry learning \\
Articifial context & Real world context
\end{tabular}


Analisis Teknologi Informasi dan Komunikasi Dalam Interpersonal Relationship

Kehumasan Persekolahan

5. Peran dan manfaat TI bagi Lembaga Pendidikan

Individual Relation yang dipernakan warga sekolahnya mampu memanfaatkan Teknologi Informasi secara efektif. Berikut beberapa syarat yang ditemukan dari hasil studi mengenai terwujudnya efektivitas aktor IR dalam praktek kehumasan di persekolahan, yaitu:

a) Sekolah perlu memiliki perangkat teknologi informasi untuk keperluan administrasi sekolah.

Darmawan, (2017:45), menjelaskan bahwa manfaat dari TI yaitu:

a) Pendidik yang belum memiliki kemampuan untuk menggunakan komputer. Dalam hal ini perlu ada penekanan kepada para pendidik agar mereka memiliki kemampuan untuk menggunakan teknologi informasi.

b) Pendidik dapat mengikutsertakan keunggulan teknologi informasi dalam pemberian tugas kepada para peserta didik.

c) Pendidik dapat menugasi pesrta didik untuk bermain di komputer sesaat sebelum pelajaran di mulai berkenaan dengan topik yang akan diajarkan.

d) Pendidik dapat menugasi para peserta didik untuk mengumpulkan sejumlah informasi tertentu dari internet serta menyusun laporan tertulis tentang kumpulan informasi itu.
Hasil studi menunjukkan bahwa lembaga pendidikan persekolahan akan memperoleh pencitraan positif ketika

b) Sekolah perlu menyediakan teknologi informasi untuk keperluan pembelajaran peserta didik.

c) Sekolah menyediakan komputer untuk membelajarkan dan disimpan diruang komputer serta sekolah harus sudah mengintalasi jaringan sekolah yang menghubungkan ruangan dan gedung sekolah.

Berikut adalah manfaat dari TI, dimana menurut Abdulhak, dan

e) Sejumlah kegiatan pembelajaran yang biasanya dilakukan melalui transparansi, slide, film atau video tape kini sudah dapat dapat dilakukan melalui teknologi informasi yakni komputer.

\section{Teknologi Informasi Sebagai Jembatan Menuju Realitas Pembelajaran}

Perkembangan teknologi informasi yang mampu mengolah, mengemas dan menampilkan serta menyebarkan informasi pembelajaran telah mampu mewujudkan virtual learning. Dicontohkan dengan munculnya E-learning, dimana secara realitas bahwa pembelajaran itu tidak sulit walaupun dibatasi ruang dan jarak yang tidak mungkin jika dilakukan, mampu diwujudkan melalui konsep $e$ learning.

Beberapa manfaat yang dapat digunakan antara lain sebagai berikut : 

a) Memperluas "background knowledge" pendidik.
b) Pembelajaran yang dinamis dan fleksibel.
e) Implementasi SAL-CBSA.

\section{METODE PENELITIAN}

Metode penelitian yang dilakukan adalah metode penelitian deskriptif, yaitu menguraikan atau menggambarkan permasalahan yang diteliti dengan menggunakan tulisan. Penelitian ini dilakukan dengan cara menganalisis permasalahan yang ada yang telah dikemukakan di berbagai referensi internet kemudian membandingkan sehingga mendapatkan hasil dari penelitian ini. Penelitian ini

Pesatnya perkembangan teknologi informasi dan komunikasi yang berdampak pada kecepatan dan kemudahan akses hubungan antar belahan dunia satu dengan dunia lainnya, telah menghilangkan sekatsekat antar negara di dunia dan menjadikan dunia ini seolah bagaikan perkampungan kecil. Perkembangan ICT tersebut telah membuat sendi-sendi kehidupan masyarakat yang ada terpengaruh baik secara positif maupun negatif. Jika perkembangan ICT tersebut dapat dikelola dan dimanfaatkan dengan baik, maka akan dapat berpengaruh positif terhadap pembangunan kualitas sumber daya manusia termasukperformance-nya, sebagaimana dijelaskan oleh Campbell et al (1993) mengatakan, "Performance is what the organization hires one to do and do c) Mengatasi keterbatasan bahan ajar.

d) Kontribusi dan pengayaan bahan ajar.

menggunakan data-data yang ada di internet, dengan cara menggali semua informasi yang ada di internet mengenai topik penelitian yang dilakukan. Sehingga penelitian ini tidak menggunakan alat-alat khusus, penelitian ini hanya menggunakan media yang dapat terkoneksi ke internet, yaitu komputer dan handphone.

\section{HASIL DAN PEMBAHASAN}

\section{Bentuk -bentuk Pemanfaatan ICT dalam Praktek Kehumasan}

well. Namun sebaliknya, jika perkembangan tersebut tidak dapatt dikelola dan dimanfaatkan dengan baik, justru akan dapat berpengaruh negatif terhadap pembangunan SDM yang ada.

Kemajuan ICT yang demikian pesat serta potensi pemanfaatannya secara luas telah membuka akses, komunikasi jarak jauh secara langsung maupun tidak langsung yang efektif, maupun membuka peluang untuk pengelolaan dan pendayagunaan informasi dalam volume yang besar secara cepat dan akurat. Kenyataan telah menunjukkan bahwa disamping dapat berpengaruh negatif, pemanfaatan ICT merupakan faktor yang sangat penting dalam mendukung kemajuan pendidikan. Menurut Krisnadi (2009) prinsip prinsip yang perlu diterapkan dalam pemanfaatan ICT yaitu: Pemanfaatan ICT dalam pendidikan sebaiknya mempertimbangkan 
Analisis Teknologi Informasi dan Komunikasi Dalam Interpersonal Relationship

Kehumasan Persekolahan

karakteristik peserta didik, pendidik, dan tenaga kependidikan dalam keseluruhan pembuatan keputusan ICT;

Pemanfaatan ICT sebaiknya dirancang sosial, maupun ragawi;

Pemanfaatan ICT sebaiknya menumbuhkan kesadaran dan keyakinan akan pentingnya kegiatan berinteraksi langsung dengan manusia (tatap muka), dengan lingkungan social- budaya (pertemuan, museum, tempat - tempat bersejarah), dan lingkungan alam (penjelajahan) agar tetap mampu memelihara nilai - nilai sosial humaniora (seni dan budaya), dan kecintaan terhadap alam sebagai anugerah dari Tuhan Yang Maha Esa; (4) Pemanfaatan ICT sebaiknya menjaga bahwa kelompok sasaran tetap dapat mengapresiasi teknologi komunikasi peranan yang penting dalam berbagai bidang, termasuk dalam bidang pendidikan. Salah satu penerapan TIK dalam bidang pendidikan antara lain pemanfaatan sarana multimedia dan media Internet dalam proses pembelajaran (Law. N, et.al. 2008). Pemanfaatan sarana multimedia dalam proses pembelajaran diwujudkan melalui modul-modul pembelajaran yang lebih interaktif dan menarik minat pembelajar, misalnya penggunaan flash, adanya penjelasan melalui media suara/ audio dan penambahan fitur-fitur yang dapat meningkatkan partisipasi aktif dari pembelajar. Sedangkan dengan pemanfaatan media Internet dalam proses pembelajaran diharapkan akan mempermudah pembelajar dalam mendapatkan informasi yang dibutuhkan, sehingga diharapkan pembelajar akan aktif mencari informasi untuk memperkuat minat dan motivasi pengguna untuk menggunakannya semata guna meningkatkan dirinya, baik dari segi intelektual, spiritual (rohani), yang sederhana dan kegiatan - kegiatan pembelajaran tanpa ICT karena tuntutan penguasaan kompetensi terkait dalam rangka mengembangkan seluruh potensi siswa secara seimbang; (5) Pemanfaatan ICT sebaiknya mendorong pengguna untuk menjadi lebih kreatif dan inovatif sehingga tidak hanya puas menjadi konsumen informasi berbasis $I C T$.

\section{Masalah yang muncul dalam pembelajaran TIK}

Pada saat ini, Teknologi Informasi dan Komunikasi (TIK) memegang

dan pengetahuan yang dibutuhkan. Namun pada kenyataannya, penerapan TIK dalam bidang pendidikan di Indonesia masih dalam tahap awal dan masih belum termanfaatkan secara maksimal.

Kendala-kendala penerapan TIK di bidang pendidikan antara lain disebabkan oleh belum meratanya infrastuktur yang mendukung penerapan TIK di bidang pendidikan merupakan permasalahan awal yang harus segera diselesaikan oleh pihak yang berwenang, karena tanpa adanya infrastruktur yang mendukung maka penerapan TIK di bidang pendidikan hanya akan menjadi impian semata. Infrastruktur merupakan komponen yang sangat penting yang berfungsi sebagai modal awal dan utama dalam penerapan TIK di bidang pendidikan. Pada saat ini, terdapat kecenderungan bahwa hanya daerah 
tertentu saja yang mendapatkan akses TIK. Hal ini dikarenakan masih banyak daerah yang bahkan untuk memilki akses telepon saja tidak ada, apalagi untuk akses terhadap Internet. Padahal

dikhawatirkan bahwa potensi sumber daya manusia yang dimiliki daerah tersebut akan terbuang dengan percuma dan tidak dapat dimanfaatkan untuk kemajuan bangsa Indonesia pada umumnya.

Kendala lainnya yang perlu diselesaikan adalah ketidaksiapan sumber daya manusia untuk memanfaatkan TIK dalam proses pembelajaran. Ketidaksiapan ini dikarenakan pola kebiasaan pembelajaran yang masih belum menganggap penting peranan TIK dalam meningkatkan citra sekolah yang unggul. Mereka cenderung sudah merasa puas akan materi yang telah diberikan oleh pengajar secara langsung, sehingga pengajaran dan pembelajaran di kelas; (b) Pandangan bahwa teknologi baru potensi untuk mendukung pendidikan di seluruh kurikulum; dan (c) Memberikan kesempatan untuk komunikasi yang efektif antara guru dan siswa dengan cara yang belum mungkin dilakukan sebelumnya.

\section{Upaya Menerapkan TIK dalam Dunia Pendidikan}

Untuk mengatasi kendala-kendala tersebut diperlukan langkah-langkah penyelesaian yang sekaligus berfungsi sebagai prasyarat keberhasilan penerapan TIK dalam pembelajaran. Menurut Mahmud (2008:13) dalam bukunya yang berjudul ICT Untuk Sekolah Unggul, terdapat beberapa sesungguhnya banyak sekali potensi sumber daya manusia unggul yang dimiliki oleh daerah tersebut. Jika hal ini terus berlangsung seperti ini maka

menyebabkan mereka tidak mau/malas untuk mencari informasi tambahan yang ada di internet walaupun sarana dan infrastruktur sudah mendukung dalam penerapan TIK. Terkadang kendala ini jauh lebih susah untuk dipecahkan daripada tidak adanya infrastruktur yang mendukung TIK, hal ini karena biasanya lebih susah untuk mengubah pola tingkah laku/kebiasaan dari seseorang, (Gefen. (2002). Oleh karena itu, perlu adanya kesadaran dari setiap individu pembelajar untuk memanfaatkan dan menerapkan TIK dalam metode pembelajarannya. Teknologi modern (ICT) banyak menawarkan di dunia pendidikan, yakni : (a) Meningkatkan

persyaratan agar dapat menerapkan pembelajaran berbasis teknologi informasi dan komunikasi, yaitu tersedianya sarana prasarana yang menunjang pembelajaran berbasis TIK. Beberapa persyaratan yang harus dipenuhi dalam menerapkan pembelajaran berbasis TIK adalah :

a) Pembelajar dan Pengajar harus memiliki akses terhadap teknologi digital dan Internet dalam kelas, sekolah, dan lembaga pendidikan. Ini berarti sekolah harus memiliki sarana prasarana yang memadai yang berkaitan dengan teknologi informasi dan komunikasi, seperti tersedianya komputer/laptop, jaringan komputer, internet, 
Analisis Teknologi Informasi dan Komunikasi Dalam Interpersonal Relationship

Kehumasan Persekolahan

laboratorium komputer, peralatan multimedia seperti $\mathrm{CD}$, DVD, Web Camera dan lain-lain;

b) Harus tersedia materi yang berkualitas, bermakna, dan

c) komputer, seperti CD, DVD Pembelajaran Interaktif;

d) Pengajar harus memiliki pengetahuan dan keterampilan dalam menggunakan alat-alat dan sumber-sumber digital untuk membantu pembelajar agar mencapai standar akademik;

e) Harus tersedia anggaran atau dana yang cukup untuk mengadakan, mengembangkan dan merawat sarana prasarana Teknologi Informasi dan Komunikasi tersebut; dan

f) Adanya kemauan dari semua pihak, dalam hal ini guru dan peserta didik untuk menerapkan pembelajaran dengan dukungan tersedianya saluran atau sarana yang dapat dipakai untuk menyiarkan program pendidikan. Namun, kenyataannya di Indonesia baru memasuki tahap mempelajari berbagai kemungkinan pengembangan dan penerapan TIK. Hal ini disebabkan adanya berbagai kendala yang ada dalam usaha pemanfaatan TIK di dunia pendidikan Indonesia. Hal ini membuktikan ketertinggalan Indonesia dibandingkan dengan negara-negara lain, seperti Israel, Italia, dan Jepang. Di negara tersebut, penggunaan TIK dalam proses pembelajaran sudah merupakan hal yang lazim. Oleh sebab itu, kita bersama-sama dengan pemerintah dan dukungan kultural bagi pembelajar dan pengajar. Materi-materi itu dapat berupa materi pembelajaran interaktif yang berbantuan

teknologi komunikasi dan informasi tersebut.

\section{E. SIMPULAN DAN REKOMENDASI}

Dari penjelasan yang telah dipaparkan, dapat ditarik kesimpulan bahwa teknologi informasi dan komunikasi (TIK) membawa pengaruh yang begitu besar bagi setiap aspek kehidupan, terutama pendidikan. Kekurangan dan hambatan yang ada dalam proses pembelajaran dapat diatasi dengan memanfaatkan perkembangan TIK. Seperti yang disebutkan dalam bagian pertama pembahasan, yaitu arti TIK bagi dunia pendidikan berarti

pihak lainnya harus saling bahumembahu dalam penyelenggaraan pemanfaatan TIK di dunia pendidikan Indonesia. Karena teknologi informasi dan komunikasi menjadi kunci untuk menuju sekolah masa depan yang lebih baik.

\section{F. REREFENSI}

Abdulhak, I, dan Darmawan, D. (2017). Teknologi Pendidikan. Bandung : PT. Remaja Rosdakarya.

Campbell, J. P., McCloy, R. A., Oppler, S. H., \& Sager, C. E. (1993). A theory of performance. In E. Schmitt, W.C. Borman, \& Associates (Eds.), Personnel 
Volume 1, Nomor 2, Edisi Desember tahun 2018

selection in organizations (pp. $35-$

70). San Fransisco: Jossey - Bass.

Darmawan, D.(2007). Pendidikan Teknologi Informasi dan Komunikasi. Bandung: Arum Mandiri Press.

Systems. 2002. Volume 3, 2002 P. 27-51. Isjoni dan Mahmud. (2008). ICT untuk sekolah unggul. Yogyakarta: Pustaka Pelajar.

Krisnadi. (2009). Rancangan Materi Pembelajaran Berbasis ICT. Jakarta: PT. Gramedia Pustaka Elang.

Lucas, H. (2000). Information Technology For Management(7th any.
Darmawan. (2013). Pendidikan

Teknologi Informasi dan Komunikasi. Bandung: Rosdakarya.

Gefen. (2002). Customer Loyalty In ECommerce. Journal of The Association For Information

$E d$.). NewJersey:Irwin/McgrawHill.

Nancy Law, Willem J. Pelgrum., Tjeerd Plomp. (2008). Pedagogy And ICT Use In Schools Around The World. Hongkong : Faculty of Education, The University of Hongkong.

Rogers, E.M.(1986). Communication Technology. NewJersey:PrenticeHall Comp 